\title{
HOMELESSNESS: A CRITICAL APPROACH TO ARCHITECTURE AND PLANNING
}

\author{
RALPH D. JOHNSON \\ Community Design Center, School of Architecture, Montana State University, USA
}

\begin{abstract}
In the fall of 2016, Professor Ralph Johnson of the School of Architecture at Montana State University was approached by Connie Campbell-Pearson, a Deacon of the St. James Episcopal Church and homeless advocate. Deacon Campbell-Pearson asked what Professor Johnson knew about tiny homes and if they could be utilized to house the homeless. This raised two interrelated questions: What do we know about tiny homes and what is known regarding issues associated with housing the homeless? The answer to the first question is that the vast majority of information available regarding tiny homes is anecdotal and without rigorous critique. On the other hand significant academic research has been published regarding the social, medical and economic conditions associated with housing the homeless. In response to the question "could tiny homes be used to house the homeless?", students in a sequence of Community Design Studios researched the social, cultural and economic conditions associated with homelessness and designed, tested and constructed a prototype micro-shelter based on Heidegger's concept of "dwelling". Construction of the first of four prototypes "micro-dwellings", intended for a Housing First Community to be developed by the Gallatin Human Resource Development Council (HRDC), was completed in the spring of 2018.

Keywords: architectural education, design-build, homelessness, Housing First, tiny homes, Martin Heidegger, Bozeman Montana.
\end{abstract}

\section{INTRODUCTION}

Housing First has emerged as a viable strategy for addressing homelessness among the chronically homeless. It is based on the belief that people need a place to live before they can effectively address their heath, neuroses, substance abuse, diet and role in society. There are two means by which the Housing First strategy has been implemented. The first, scatteredsite housing, was developed in the 1990s in cities where adequate housing was available for the homeless to be located in existing housing units. As early as 1994, in communities where housing demand exceeded availability project-based programs emerged. Project based programs utilize housing units specifically designed to accommodate the homeless and are arranged in a manner such that onsite supportive services can regularly be provided to the residents. Both scattered and project-based housing first programs have shown significant success in reducing the economic cost of homelessness, demands on public services and addictions while increasing the retention of residents. More recently, in an effort to meet aspirations to house the homeless, communities and non-profit organizations have constructed various size individual shelter units of varying quality and organized in a manner described as tiny home villages for the homeless.

This paper evaluates tiny homes relative to the International Building Code, the success of the Housing First model and the potential of micro-dwellings to meet the social, cultural, economic and health goals of Housing First. This is followed by documentation of the design and construction of a prototype micro dwelling by students in four (4) sequential community design studios in the School of Architecture at Montana State University in Bozeman, Montana, USA. 


\section{WHAT IS A TINY HOME?}

Until recently the definition of a tiny home was vague. Proponents of the tiny house movement in the United States suggested that a home of less than 1,000 square feet (93 square meters) was small and that a tiny home was characterized as less than 400 square feet (37 square meters). There was generally no distinction between a traditional stick frame home, one built on a trailer frame for a recreational vehicle, a modular home built offsite and intended to be placed on a site-built foundation or a home constructed from shipping containers.

The International Residential Code (IRC), from its first edition in 1997 through the 2015 edition made no distinction for residential types based on the size of the dwelling unit and simply required that every dwelling have at least one habitable room not less than 120 square feet (11.1 square meters) of gross floor area (R304.1) and that other rooms, except kitchens must have a floor area of not less than 70 square feet (6.5 square meters) (R304.2). Additionally, with the exception of the kitchen, habitable rooms must have a horizontal dimension of not less than 7 feet (2.1 meters) (R304.3) and mezzanines require 7 feet (2.1 meters) above and below (R325.2). The 2018 IRC has been amended to include Appendix Q, which defines a tiny house as a dwelling that is 400 square feet (37 square meters) or less in floor area excluding lofts. Lofts have been defined in terms of area and headroom with significantly reduced requirements associated with stairs and means of egress. This official definition is important because it provides a legal basis for the housing type to be recognized by lending institutions and insurance agencies, a specific basis for a Certificate of Occupancy and perhaps most importantly a necessity for zoning codes to accommodate the tiny house building typology.

Equally significant the definition clarifies what is not a tiny house. It is not a trailer type recreational vehicle conforming to the American National Standards Institute (ANSI) part 119.5 regulated by the Recreational Vehicle Industry Association (RVIA) nor is it a manufactured home conforming to the Manufactured Home Construction \& Safety Standards administered by HUD nor is it a "trailered" recreational vehicle conforming to the National Fire Protection Association standards part 1192. Typically zoning ordinances accommodate these building types in special districts segregated from single family residential districts. Thus the vast majority of tiny homes today are located outside of municipalities with zoning regulations, in mobile home parks or manufactured home districts.

If government entities throughout the United States adopt the 2018 IRC Appendix Q their building codes will ensure a level of construction, electrical and heating systems, insulation, and life safety conformance that will make tiny homes equivalent to other single-family residential units and because they are a legal form of housing, zoning codes will need to be developed that ensure land is available within the municipality to accommodate the tiny house residential typology. This is particularly important because zoning ordinances have typically set minimum residential floor areas greater than 400 square foot and often establish minimum lot sizes based on set-back requirements for the front, rear and side yards related to the minimum floor area. Thus for a tiny home residential district, lot sizes might easily be as small as 1600 square feet (149 square meters) permitting space for two cars, a 20'x20' (6 x 6 meters) residence, five foot (1.5 meters) side yard setbacks and 25 feet ( 7.6 meters) distributed between the front and rear yards.

\section{HOMELESSNESS}

The US Department of Housing and Urban Development conducts a point in time survey on one night in January each year. The 2017 survey estimated that there were 553,742 people experiencing homelessness in the United States of which $35 \%$ lived in an unsheltered 
condition such as on the street, under a bridge, on undeveloped land or in a vehicle. Of these $71 \%$ were men, $7 \%$ were veterans, $7 \%$ were under the age of 25 and $24 \%$ were chronically homeless individuals who have been continuously homeless for one year or longer. The unsheltered population in the U.S. increased by $9.4 \%$ between 2016 and 2017 after ten years of decline. California was the state with the largest number of unsheltered people, 91,642 (49\% of the U.S. unsheltered population) while Montana had 1,529 individuals experiencing unsheltered homelessness. For the first time since 2008, the number of chronically homeless individuals in the U.S. increased between 2016 and 2017 by 12\% (9,476 people). In Montana the increase was $7.8 \%$ of which 198 were chronically homeless individuals with approximately 20 residing in Bozeman, Montana [1].

In an effort to move beyond the statistics and literally come face to face with the homeless, students in the School of Architecture's Community Design Studio were given the responsibility to work at Bozeman's warming shelter to assist with the twice weekly shower days and to serve meals at the Human Resource Development Council's (HRDC) free kitchen. Additionally James Episcopal Church's Deacon Connie Campbell-Pearson introduced the faculty and students to numerous individuals who were chronically homeless. Personalities varied greatly as did their stories of the past, their present circumstances and their views regarding homelessness. Two stood out because they so clearly illustrated a failed social welfare system.

One was a veteran who because of a back injury suffered while in the military was classified as permanently disabled. For several years he had supplemented his veteran's disability income by driving a local delivery truck. The combined income made it possible for him to afford a rental property. Two years ago the pain in his back became so intense from driving that he had to give up the job and with it his apartment. Relatives were aware of his condition and circumstances but they did not have the resources to offer him financial support and he did not want to inconvenience them with one more person in their home. He has chosen to live in a tent, moving from place to place in the community on his bicycle throughout the year. He has his veteran's pension so can afford to "make do" in his words out of a tent but would never be able to again afford a market rate apartment in Bozeman.

The second individual was a woman who for many years, with her husband, had a dual income with which they were able to buy a house, raise their children and ultimately pay off the loan on the house. Her husband developed a heart condition and to pay the medical expenses they borrowed money with the house as collateral. Following his death she continued to work full time and meet her expenses but then, within a year of her husband's death, she had a stroke which not only brought on more medical debt but made it impossible for her to work more than every other day for half a day. Unable to make the house payments she lost her home and now lives in her car while working 12 hours a week. She had not asked her children for help because they were service workers with kids, had lost their jobs during the recession and she indicated they "could barely make ends meet themselves". Phone calls each week kept them in touch with one another but she had never discussed her stroke and felt it her responsibility to take care of herself and not "be a burden on others".

Each of these individuals indicated that his or her housing needs were minimal. If they had a place where they could be independent, prepare a meal, sleep in a space where the environment was under their control, wash and bathe on a regular basis and safely store their belongs they would be thankful beyond measure.

The woman living in her car had one revealing additional requirement. The home had to have a window overlooking her car so that she could maintain its security. It was her only possession of value and she felt she would not survive if something happened to it. The informal interactions with other members of the homeless community at the shelter and 
kitchen often revealed forms of neurosis, addictions and physical fragilities. It became apparent to the students that the chronically homeless community consisted of a broad cross section of individuals not all of whom had heart breaking stories but all of whom were in desperate need of help. It was from these interactions with the chronically homeless that the students gained a sense of empathy for their clients and an aspiration to provide them with more than shelter from the elements but instead, as Heidegger articulates a place to "dwell within the fourfold".

\section{THE COST OF HOMELESSNESS}

Cost-of-homeless studies have shown that the services provided to the homeless are significant. Medically, Dr. Stephen W. Hwang identifies un-medicated cuts, abrasions, bruises and broken bones, chronic pain such as arthritis, skin and foot problems, infectious diseases like hepatitis A, B, and C, tuberculosis, oral health, pulmonary disease, emphysema, bronchitis, hypertension, diabetes, heart and kidney disorders and mental issues as the most common health problems faced by the homeless (Hwang [2]). Additionally disease severity can be increased by factors such as delays in seeking care, nonadherence to therapy, cognitive impairment and homelessness itself. In seeking remedies the homeless visit emergency rooms and are often admitted to hospitals for care of these disorders. While the chronically homeless represent $24 \%$ of the unsheltered homeless, they consume the largest share of health, social, and justice services. Malcom Gladwell's "Million-Dollar Murray" highlighted a combination of homelessness, mental illness, and substance abuse that led to repeated and costly interactions with multiple governmental institutions estimated to exceed $\$ 1,000,000$ throughout Murray's adult life time (Gladwell [3]). Studies of the fiscal cost associated with the chronically homeless, in contrast to popular assumptions, estimate the average annual per person cost of emergency room visits, acute hospitalization, overnight shelter, incarceration, and crisis services to be as much as $\$ 30,000$ to $\$ 50,000$ per year [4]. A study conducted by the Human Resource Development Council of Bozeman, Assessing the Community Costs of Chronic Homelessness in the Gallatin Valley [5] revealed similar expenditures. Eight individuals, meeting the chronically homeless criteria and having lived in Gallatin Valley for two or more years, ages ranging from 22 to 61, agreed to the release of data regarding community expenditures related to their health, safety and welfare. The study revealed expenditures ranging from a low of $\$ 10,964$ to a high of $\$ 211,680$ resulting in an average annual cost of chronic homelessness per person of $\$ 28,305$ mirroring quite closely the national average.

\section{HOUSING THE HOMELESS}

The unique perspectives of three constituencies concerned with homelessness merged in the late 1980s and early 1990s to advocate for a new approach to addressing chronic homelessness. The general public's altruistic view was that homelessness, seen on the streets of every community, demonstrated that current strategies were not working and that something needed to change to eliminate this condition. Both public and non-profit social service agencies were faced with a growing number of homeless while funding for public housing decreased and strategies for providing effective health services were frustrated by the inability of providers to maintain contact with homeless clients. Equally significant was the realization that police, emergency room and hospital costs associated with the chronically homeless presented an economic justification for reducing homelessness.

In the early 1990's Dr. Sam Tsemberis, at Pathways to Housing in New York, proposed a radical approach to help people with mental health problems who were living on the streets. He proposed that housing was to be provided first rather than after they had completed 
rehabilitation as is typically the circumstance with linear residential treatment strategies. Linear residential treatment strategies generally require that residents must participate in social, medical, and substance abuse programs with success prior to receiving access to housing. Dr. Tsemberis' solution was to give the chronically homeless access to a home in an apartment building combined with support services delivered to them in their home. There was no requirement to stop drinking or using drugs and no requirement to accept treatment in return for housing. Support services were intended to help the users sustain their housing and promote their health, well-being and social integration within a framework that gave service users a high degree of choice and control [6].

The Pathways to Housing approach became known as "Housing First", often described as supportive housing. It is guided by the belief that people need basic necessities like food and a place to live before attending to anything less critical, such as dealing with medical problems, getting a job, budgeting properly, or attending to substance use issues. Of equal importance is the belief that exercising choice with regard to supportive service participation is likely to make a client more successful in remaining housed and improving their life. In comparing the Housing First approach to the linear approach, $88 \%$ of those in the Pathways program remained housed for up to four and a half years while the linear residential treatment approach achieved a successful retention rate of $47 \%$ [7]. One of the most complete studies was conducted by the Denver Housing First Collaborative in 2006. It revealed that emergency room costs were reduced by an average of $34.3 \%$, hospital inpatient costs were reduced by $66 \%$ and incarceration costs reduced by $76 \%$ among their 200 chronically homeless clients participating in their Housing First program. Equally important was the fact that $77 \%$ of those placed in the housing first program remained housed after two years [8]. The majority of residents in Housing First communities take part in the optional support services [9] and participate in job training programs, attend school, discontinue substance use and have fewer instances of domestic violence [10].

The concept of Housing First has been implemented in two ways. As illustrated by the programs at Pathways to Housing in New York City and Denver's Housing First Collaborative, scattered-site programs were developed in cities where adequate housing was available and the chronically homeless could be offered individual housing units located throughout the community. More recently, in communities where housing demand far exceeds availability and practically no vacant affordable housing units exist, project-based programs have emerged. Project-based programs utilize housing units specifically designed to accommodate the homeless and are arranged in a manner such that centrally located supportive services can regularly and in some instances spontaneously be provided to the residents.

The Downtown Emergency Service Center (DECS) in Seattle, WA began development of project-based apartment buildings in 1994 and currently operates 12 apartment buildings with more than 1,100 units of supportive housing throughout Seattle. To increase the opportunities for success residents in each of the housing sites have access to supportive services at all times. The services include mental health and substance use disorder treatment, health care, daily meals, case management and payee services, medication monitoring and weekly community-building activities. These services have resulted in $92 \%$ fewer nights in emergency shelters, $87 \%$ fewer admissions to sobering centers, $45 \%$ fewer bookings in jail, $41 \%$ fewer medical expenses, and a $63 \%$ increase in abstinence from drinking alcohol. On average, after two years, DECS has experienced an $84 \%$ retention rate among their residents. For their most recent building 79 chronically homeless men and women were offered housing and 75 accepted, dispelling the notion that many of the homeless are content to be homeless [11]. 


\section{THE HOUSING FIRST VILLAGE CONCEPT}

Within the housing first project typology a recent strategy has evolved in response to the capital-intensive construction or renovation of apartment buildings. Called villages these project-based housing first communities consist of small individual units often built by volunteers. This was the basis of Deacon Connie Campbell-Pearson's initial contact with Professor Johnson and the School of Architecture's Community Design Center. She wanted to know if tiny homes, built by community service organizations, church groups, and local volunteers could serve to meet the needs of the homeless in Bozeman, Montana. Research by students in the Community Design Studio revealed that there were fewer than 15 such villages across the United States and that their characteristics varied dramatically. Among the least expensive and smallest unit size, the Tiny Home Village in Seattle, WA, incorporated units that are 96 square feet ( 9 square meters) and served as a living/sleeping space with community toilets and shower facilities. No cooking or service facilities were located on the site. Each unit cost approximately \$2,200 and was designed to be moved to another site after the one-year emergency housing site permit expired. At the opposite end of the spectrum, units in The Cottages at Hickory Crossing in Dallas TX. cost approximately $\$ 100,000$ each and provided a living room, kitchen, private bedroom and full bath in 330 square feet (30.7 square meters) plus a front porch. Supportive services are provided on an adjacent site but not within the village.

Utilizing Montana State University Undergraduate Scholarship funding these two villages plus a third, Quixote Village in Olympia, WA were investigated through on-site visits by students in the Community Design Studio. This research revealed that Quixote Village could serve as an appropriate precedent for a village in Bozeman. The units are 144 square feet (13.4 square meters) with a front porch and have a living/sleeping space with a separate $1 / 2$ bath with sink and toilet. The units cost $\$ 19,000$ each and were built by professional construction workers. The porches face a central community lawn and walkway connecting all of the units to the community building. The two-acre ( 0.8 hectare) site includes 30 units organized around a central open space, garden and retention ponds. The community building includes a communal kitchen, community room, showers and laundry facilities in addition to staff offices and a meeting room in the centrally located 2,640 square foot ( 245 square meter) building.

In interviewing the residents, the students found a high value was placed on the front porches because they promoted interaction, a means of getting to know your neighbors as they walked the path in front of your home and helped to create a sense of community. The space between the front porch and the walkway was, in many instances, decorated with unique and interesting personal touches and small flower gardens. All of the residents interviewed expressed their pride and a sense of independence associated with the privacy and responsibility for their home. Each resident shared in responsibilities for the governing the village and maintenance of common spaces thus developing a strong sense of community and neighborliness. The village arrangement was the result of workshops led by Garner Miller of MSGS Architects in which residents of a tent camp called Camp Quixote identified their ideal housing solution to be a conditioned shelter for each resident with shared bathing and cooking facilities rather than a room or apartment within a larger building in which they would have no sense of ownership. This pride of ownership, responsibility for shared governing and communal responsibility was clearly apparent in the interviews and has resulted in only one resident choosing to leave the community for the streets since 2013.

Located adjacent to an industrial park outside of Olympia, when land and development expenses are factored in, the total per-unit cost was $\$ 88,000$, approximately half the cost of a conventional studio apartment. Hundreds of volunteers have taken turns serving as camp 
"hosts", getting to know residents and forming friendships to the degree that the village "has changed the way our community thinks about homeless people and homelessness" (Lubenau [13]).

\section{BOZEMAN, MONTANA}

Bozeman, Montana is located in the Northern Rockies and frequently identified as one of the best places to live in the United States. In 2017 alone, it was named the 10th best place to live, work and prosper by Money Magazine and eighth best place to live in the United States by the Men's Journal Top 10 survey. It is a university town with numerous high-tech businesses and a thriving tourist industry centered on extraordinary recreational opportunities for skiing, fly fishing, mountain hiking and biking all within 20 minutes of downtown. The population of the City is approximately 45,000 but it serves a regional population of over 100,000. In contrast to the stories of Bozeman's beauty and desirability, based on the 2017 Annual Homeless Assessment Report (AHAR), the Gallatin Human Resource Development Council (HRDC) estimates that there are about 115 homeless individuals in Bozeman on any day and that 20 to 30 are chronically homeless.

In May of 2018 the average rent for an apartment in Bozeman, MT was \$1,205 with studio/one-bedroom units renting on average for $\$ 749$ per month with rental rates rising at $7.8 \%$ per year. Additionally there is effectively no-vacancy rate. It was clear that a scatter site housing first approach was not going to be tenable in Bozeman because there are simply no apartments available and not only was the cost of rent high, but it was rising. This led to two conclusions based on the research completed by the Community Design Studio students: 1) a project-based approach would be best suited for Bozeman and 2) borrowing from the lessons learned from the Quixote Village, 30 small, individual units, could likely fit on two acres at significantly less cost than building an apartment building.

\section{THE DESIGN CHALLENGE}

Following Deacon Connie Campbell-Pearson's lead, HRDC partnered with the Community Design Center to develop a prototype tiny shelter and village plan for a future Housing First Village. Deacon Campbell-Pearson and HRDC determined that the Village should be within the City of Bozeman's municipal boundaries, on the community bus line, near a grocery store and that the homes needed to be designed in a manner that would permit volunteers to build the units. To build within the City limits required that the units be designed to conform to the International Residential Code, receive a building permit and fulfill all of the code regulations to receive an occupancy permit. Deacon Campbell-Pearson was also adamant that the tiny homes needed to be designed such that they would provide a sense of pride, human dignity, and more than simply shelter for the residents. With these design challenges the Community Design studio students first developed sketches and then tested their ideas by utilizing tape on the studio floor to give them a better sense of the size and organizational strategies that they were proposing in their plans. They then built small models and began to form collaborations among like-minded students.

It was at this point that the students were challenged to go beyond the idea of building mere shelters for a village that some of the homeless as well as community members feared would become a symbol of homelessness, a failed social welfare system and a potential ghetto. Could the village instead act in the manner of Martin Heidegger's "bridge", gathering "in its own way earth and sky, divinities and mortals...from which something begins its presencing" [14]. Heidegger, widely acknowledged to be one of the most original and important philosophers of the 20th century, engaged in a search to understand the concept of being from a Presocratic position, which led him to advocate a phenomenological method to 
studying the nature of being, of consciousness, and the objects of direct experience. Martin Heidegger's essay, Building Dwelling Thinking, was introduced to the students to help address this issue. In this essay the concept of "presencing" is adopted by Heidegger to express the idea of disclosing a presence beyond its physical manifestation, to reveal its meaningfulness.

To a degree this had been achieved in Quixote Village. Because of the work of the community "hosts" a socio/cultural integration of the village and the community had occurred. Not only were the residents of Quixote Village proud of the village but the community saw the village as a successful model of what could be achieved in an effort to eliminate homelessness. Deacon Campbell-Pearson was certain that if the shelters for Bozeman's Housing First Village were constructed by volunteers, service organizations, and church groups a similar "presencing" could occur to the benefit of both the village and the City.

The challenge remained however for the students. Deacon Campbell-Pearson had a vision of tiny homes for the homeless, not mere shelters to keep out the weather. Shelters could more or less be easily built but her goal was much more insightful. The concept of a home was at the core of her aspirations for the homeless, a place that would impart a sense of security, the comfort of belonging and a pride of ownership. Above all she sought to provide the homeless with the opportunity for respect and dignity and she saw this intimately linked to a place of their own, a home. But for the students this raised the question of what constitutes a home. In many respects Deacon Campbell-Pearson's intuition parallels that of Heidegger's concept of "dwelling". Heidegger states that "the fundamental character of dwelling is...sparing and preserving". He defines sparing as to do no harm and thus in dwelling we reside at peace within a freedom that safeguards our own nature. He articulates preserving as to remain, to stay in a place and to be at peace, preserved from harm and danger. Heidegger further argues that a building that "preserves the fourfold by bringing the presencing of the fourfold into things" has the potential to become a dwelling.

So what might architectural students do to engender a building with the qualities that enable the resident to "dwell"? Heidegger's fourfold begins with where we reside, on the earth, the place of nature where plants and animals comingle with the landscape. The earth's counter point is the sky where the sun brings life to the earth, the aspects of day and night as well as the changing of seasons. The divinities are the third element of the fourfold. The divinities represent our communal values, our aspired to social beliefs and responsibilities. Counterpoised to the divinities are we ourselves, the mortals, frail and compromised as we live before the divinities, under the sky and on the earth. Accepting this as a working definition of a home in support of Deacon Campbell-Pearson's design challenge the students devised interwoven strategies in seeking to imbue the "thing", the building, with characteristics that would promote the presencing of the fourfold and thus offer the opportunity for dwelling.

The first strategy was to anchor the building to the ground by creating landscape planters, watered from a rain barrel, where flowers could abound and attract the wildlife of the place. This strategy of course was dependent upon the sky to provide the sun and rain to make the landscape successful, but the sky was also responded to by angling the roof upwards to bring in natural light without compromising the privacy of the individual. Operable windows were arranged to promote cross ventilation and link the inside of the building to the events of the day and night. Lastly, with regard to the sky a front porch was provided with an awning that permits the resident to sit outside protected from but intimately related to the sun, rain or snow. The porch in turn serves to promote engagement with the community, to link the resident to the social expectations of the community and to provide a place where one can 
engage neighbors, share in their goals and aspirations, become familiar with their needs and desires and take responsibility for their well-being. Lastly the presencing of mortals is revealed in the use of reclaimed lumber and stylized weathered metal elements on the exterior and reclaimed, repurposed former campus dormitory cabinetry used for the ceiling and other elements of the interior. Each of these attempts to promote the presencing of the fourfold is multi-valent in that each singular element of the strategy serves a dual purpose. That which recognizes the earth also serves to reveal the sky, the divinities and the mortal mutually ascribing the oneness of the fourfold.

\section{THE DESIGN OF THE DWELLING}

Following a review of the plans and models by Deacon Campbell-Pearson and members of the HRDC staff, two full scale cardboard models with simulated and actual furnishing were built and tested by students (Fig. 1), faculty, HRDC staff, members of the homeless community and the general public at an exhibition which was featured in newspaper articles and television broadcasts. The cardboard mock-ups were intended to test the viability of design strategies. Could the space and objects within it begin the "presencing" of Heidegger's phenomenological experience of dwelling? The mock-ups proved invaluable in this regard, as those who visited commented that the units "felt like a home". The combination of high ceilings, enriching the space with light from clearstory windows, an open plan achieved by utilizing low mobile clothes closets and windows arranged to extend the apparent length and width of space created and interior experience that liberated the senses beyond each model's tiny footprint.

As a direct result of the exhibition, community donors contributed to a fund to build a prototype dwelling. Additionally the Montana State University Office of Outreach and Engagement provided the Community Design Center with a grant of $\$ 5,000$ in support of building the prototype and the Office of Family and Graduate Housing made land available on campus.

The evaluation of the full-scale models resulted in a synthesis design by the students which combined attributes of both mock-ups. A final plan and character was agreed upon, from which construction documents could be created for a 145 square foot (13.5 square meter) micro dwelling. This concluded two (2) semesters of research and design by the initial group of 12 Community Design studio students.

\section{THE MAKING OF THE PROTOTYPE DWELLING}

In the summer of 2017 six (6) new students enrolled in the Community Design Center studio with the responsibility to create construction documents for the first prototype dwelling and

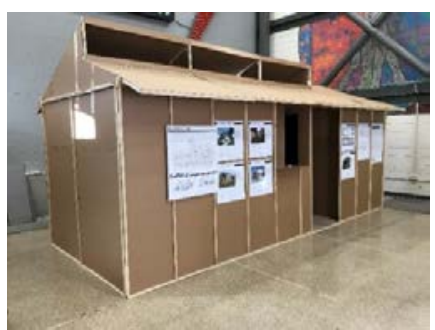

(a)

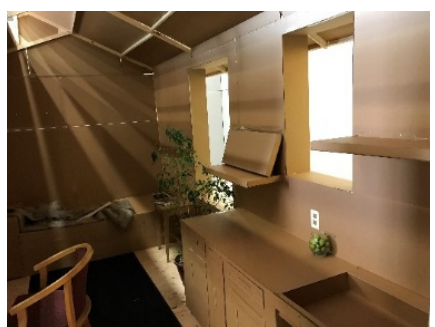

(b)

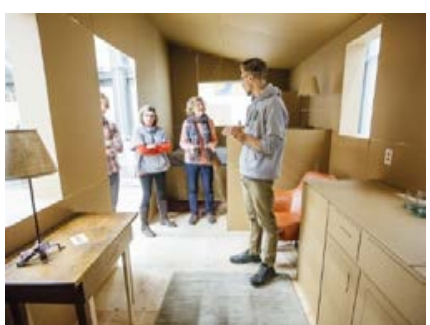

(c)

Figure 1: (a) Cardboard mock-up exterior; (b) Cardboard mock-up interior; (c) Cardboard mock-up interior. 
commence construction. The dwelling structural system consists of 14" (35.6 centimeters) Trus Joist I (TJI) floor and 16" (40.6 centimeters) ceiling joists with 2 x6 studs at 24" (61 centimeters) on center with $3 / 4$ " (2 centimeters) sheathing wall construction. In conformance with the International Energy Conservation Code the floor was insulated with R-38 and the ceiling with R-49 fiberglass batts. For the walls R-13 insulation was placed in the cavity and on the exterior, one layer of rigid insulation parallel to the ground combined with a second layer placed perpendicular to the first resulted in R-10 + R-13 insulation for a combined R26. Pella Corporation donated Low-E InsulShield double pane windows for the dwelling and all of the windows were shaded by student designed and constructed metal canopies. Heating is provided by a single 1,000-Watt in wall electric heater, which throughout the winter proved to be practically unnecessary once a comfortable temperature had been reached. To ensure adequate air flow one pair of Lunos e2 through wall heat, ventilation recovery units were installed, which operate at 9/18/22 CFM flow rates.

The intention is to transport the dwelling to the future HRDC Housing First Village so pier foundations support wooden rails carrying the floor framing system thus making it relatively easy to disconnect the 8'6" (2.29 meters) wide dwelling and move it by trailer. Construction documents were submitted through the Montana State University Office of Campus Planning Design and Construction and a building permit was issued by the Bozeman City Building Department in July of 2017.

Construction began with prefabrication of the floors and walls in the School of Architecture Fabrication Labs followed by erection and assembly on the site where utilities had previously been installed by the Montana State University Facilities Services (Fig. 2).

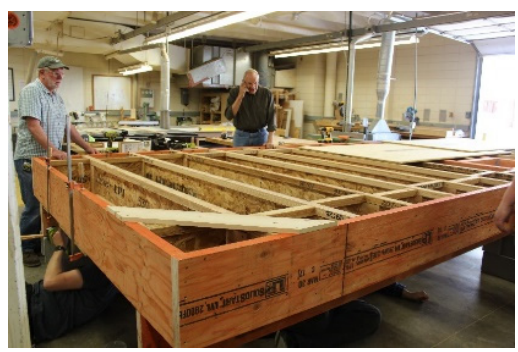

(a)



(b)

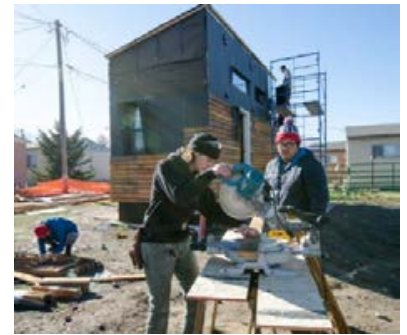

(c)

Figure 2: (a) Prefabrication of floor frame; (b) On-site erection; (c) Student carpenters.

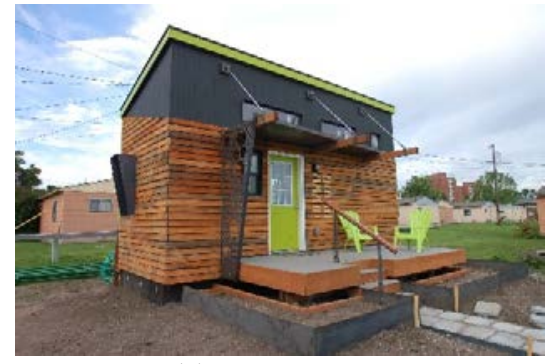

(a)

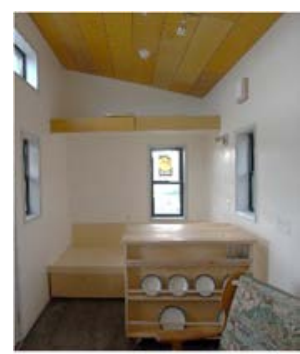

(b)

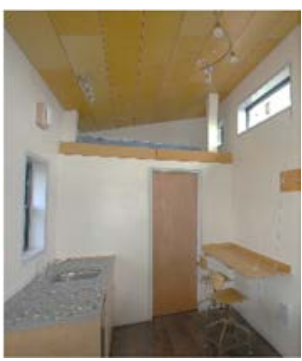

(c)

Figure 3: (a) Completed dwelling exterior; (b) Dwelling interior; (c) Dwelling interior. 
The exterior was substantially completed by the third group of six (6) Community Design Studio students in the Fall of 2017 and the fourth studio of six (6) students completed the first prototype Micro Dwelling for the Homeless in the spring of 2018 (Fig. 3).

\section{CONCLUSION}

A tiny home, designed with the intention of protecting the residents from harm and danger, affording them the opportunity to live in peace within nature and among others and built in a manner that demonstrates respect for the resident has the potential to cultivate Martin Heidegger's concept of dwelling. Adopting the Housing First strategy of supportive services to a village of such dwellings will create a community of people who feel protected, respected and connected in a manner that generates trust not only among the residents but within the larger community. When people trust each other they can be much more accepting of diversity, they can become adaptable and they can think about a future in which the present matters. In this way the village's presence will be perceived by the entire community as contributing to the community's social and cultural wealth.

With regard to architectural education, the role of the Community Design Center studio served to connect, in a meaningful way, students to a subset of the community that they were largely unfamiliar with in an intimate manner. This fostered an empathy from which critical decisions could be made not only during the traditional design phase but during the build/design phase. Engaging in the craft of building, gave students a much richer understanding of the construction process and its endless opportunities for engagement with the client's physical and emotional needs. Lastly, utilizing a small group of students in each phase resulted in 36 students having shared in the pride of the accomplishments in a critical approach to architecture and community engagement.

\section{REFERENCES}

[1] The 2017 Annual Homeless Assessment Report (AHAR) to Congress Part 1 December 2017, U.S. Department of Housing and Urban Development, Office of Community Planning and Development, 2017. www.hudexchange.infor/resources/documents/ 2017-AHAR-Part1.pdf. Accessed on: 10 Apr. 2018.

[2] Hwang, S.W., Homelessness and health. Canadian Medical Association Journal, pp. 229-233, 23 Jan. 2001.

[3] Gladwell, M., Million-Dollar Murray. New Yorker, 82(1), 2006.

[4] Ending Chronic Homelessness in 2017, United States Interagency Council on Homelessness, 2017.

http//www.usich.cov/ressources/.../Ending_Chronic_Homelessness_in_2017.pdf.

Accessed on: 13 May 2018.

[5] HRDC Final Report 03.17.xps_ Montana Healthcare Foundation, 2017. https://mthcf.ort/wpcontent/uploads/2018/01/HRDC-Final-Report_03.17.pdf.

Accessed on: 5 Feb. 2018.

[6] The History of Housing First - Housing First Europe Hub. http://housingfirsteurope.eu/guide/what-is-housing/history-housing-first. Accessed on: 5 Jan. 2018.

[7] Tsemberis, S. \& Eisenberg R., Pathways to housing: supported housing for street dwelling homeless individuals with psychiatric disabilities. Psychiatry Online, 1 Apr. 2000. Accessed on: 5 Jan. 2018.

[8] Perlman, J. \& Parvensky, J., Denver housing first collaborative cost benefit analysis and program outcomes report 2006. Colorado Coalition for the Homeless, $11 \mathrm{Dec}$. 
2006. https://Shnny.org/uploads/Supportive_Housing_in_Denver.pdf. Accessed on: 11 Oct. 2017.

[9] Tsemberis, S., Bulcur, L., \& Nakae, M., Housing First, consumer choice, and harm reduction for homeless individuals with a dual diagnosis. American Journal of Public Health, Apr. 2004. https://www.ncbi.nim.hih.cov/pubmed/15054020. Accessed on: 11 Oct. 2017.

[10] Einbinder, S. \& Tull, T., The Housing First program for homeless families: empirical evidence of long-term efficacy to end and prevent family homelessness. Beyond Shelter Housing - A Basic Human Right, Jun. 2007. www.beyondshelter.org. Accessed on: 11 Oct. 2017.

[11] Housing \& Health to end homelessness. Supportive Housing - DESC. https://www.desc.org/what-we-do/housing. Accessed on: 6 Jun. 2018.

[12] The South King County Housing First Pilot Report. www.csh.org/wpcontnet/uploads//2012/09/KCHA-Housing-First-Report.pdf. Accessed on: 6 Jun. 2018.

[13] Lubenau, A.-M., Site Visit: A Tiny House Village in Olympia Offers a New Model for Housing the Homeless. www.metropolismag.com/autho/annemarielubenau/ Accessed on: 20 Mar. 2017.

[14] Heidegger, M., Building Dwelling Thinking. Poetry, Language, Thought, Harper Perennial Modern Thought, New York, 2013. 